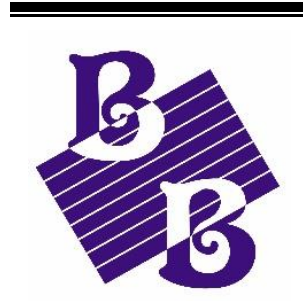

BioBacta

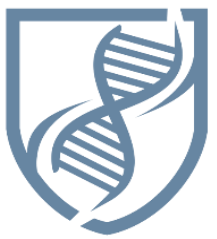

Journal of Bioscience and Applied Research

www.jbaar.org

\title{
Effect of Polyethylene and Butylated Hydroxytoluene on the histological structure and some enzymes of rat liver
}

\author{
Hassan Al-Harbia , Zaki Al-Hasawi ${ }^{b}$, Yaser Binnaser ${ }^{\mathrm{c}}$, Reem Al-Hasawid , Faiz Al-Solami ${ }^{\mathrm{a}}$ and \\ Abdullah Al- Ghamdia \\ ${ }^{a}$ Poison Control and Medical Forensic Toxicology Center, Jeddah, Saudi Arabia \\ ${ }^{b}$ Department of Biological Sciences, Faculty of Science, King Abdul Aziz University, Jeddah, Saudi Arabia \\ 'Department of Biology, College of Sciences, Taibah University, Al-Medina Al-Munawara, Saudia Arabia \\ ${ }^{d}$ Department of Chemistry Sciences, Faculty of Science and Arts, King Abdul Aziz University, Rabig, Saudi Arabia \\ * Corresponding authors: Hassan A. Al-Harbi; Email: dfhhh25@gmail.com \\ Received: May 10, 2020. Accepted: May 30, 2020. Published: June 11, 2020
}

DOI: 10.21608/jbaar.2020.116133

\begin{abstract}
This research studied the effect of polyethylene (PE), Butylated Hydroxytoluene (BHT), PE with BHT, and the thermally-treated PE on the histopathological examination and some biochemical activities of the liver of adult male mice.105 mice were divided into 5 groups. The (PE group) supplied with $20 \%$ crushed PE, the (BHT group) supplied 400mg/kg of BHT dissolved in corn oil, the (PE + BHT group) were fed with $20 \%$ crushed PE and $400 \mathrm{mg} / \mathrm{kg}$ of BHT dissolved in corn oil, the (thermally treated PE group) supplied food with $20 \%$ of crushed thermally-treated PE, and the control group. The weight of the mice was recorded before the study and after 6 weeks. Blood samples were collected to determine the liver enzymes aspartate aminotransferase (AST) and alanine aminotransferase (ALT). The animals were sacrificed; the liver was weighed before and after treatments and examined microscopically. Liver specimens were stained and examined by a light microscope. The results showed that the mean weights of the mice in PE, BHT, and PE + BHT groups were statistically reduced and the mean weights of their livers significantly $(\mathrm{p} \geq 0.05)$ increased and the enzymes AST and ALT in the blood significantly $(\mathrm{p} \geq 0.05)$ increased in comparison to the control group. The histopathological examination of the liver specimens showed significant changes with all PE and BHT treatments. The results of the current investigation suggest preventing the use of plastic in food preservation and replacing it with safe grade substance like wood materials
\end{abstract}

Keywords: Albino mice, Polyethylene, Butylated Hydroxytoluene 


\section{Introduction}

$\mathrm{PE}$ is one of the polymers used in plastic synthesis. Previous studies indicated that PE is an inert material. Recent reports about the possible hazardous effects of plastic sheets on the environment, on animal and plant lives. Several additives are added to PE for several purposes. BHT is an antioxidant that is added to PE to prevent oxidation. Several reports attributed the toxicological effects of $\mathrm{PE}$ to the migration of additives from $\mathrm{PE}$ to the surrounding environment. (Chang et al. 1977).

With today's civilized progress and rapid technological development, the plastic industry has emerged with new and easy-to-use plastic products such as bags, cups, and plastic dishes, which have been used in very large quantities to preserve meat, vegetables and most food products of all kinds. But their use extends to some types of daily food used by vendors to fill what they sell foods such as beans, yogurt, juices, and others (Shehata 1999). Studies have shown that people exposed to this substance are infected with vesicles in the bones of the limbs and inflammation of the nerves and narrowing of blood vessels (Shehata 1999). High-density PE is used in the manufacture of milk containers, thick pipes that bear pressure and water transfer, and to manufacture very thin bags used in stores (Pebsworth 1996).

The antioxidative effects of different level (200, 400,800 and 1,200 ppm) of pomposia juice and extracts as natural antioxidant compared to BHT (200 ppm) on the stability of fried sunflower oil was investigated by Ali 2010 who found that the phenolic compounds of pomposia extract at levels 800 and 1,200 ppm induced powerful antioxidant effects which were almost equal to the synthetic antioxidant (BHT) at level 200 ppm.

$\mathrm{BHT}$ is an indirect additive to food, adding to PE used in food packaging (Lanigan and Yamarik 2002). The BHT is rapidly absorbed through the digestive tract and the skin and distributed within the body. It is highly soluble in fat and its volume of distribution is estimated at $2.9 \quad 1 / \mathrm{kg}$ (Verhagen et al. 1989). Metabolism is also in the liver and part of the BHT is metabolized with metabolites in urine and bile (Takahashi 1991). The liver is the organ in which gastrointestinal food is stored and stored for use by the rest of the body. It is the mediator between the digestive system and blood (Hamoud 2003) emerges. Feeding test mice during breast-feeding doses of BHT up to $500 \mathrm{mg} / \mathrm{kg}$ (body weight) led to a change in body weight and growth parameters in infants (Meyer and Hansen, 1980). The use of $250 \mathrm{mg} / \mathrm{kg}$ of BHT resulted in pneumococcus type I, (Yamamoto et al. 1988). BHT use of $500 \mathrm{mg} / \mathrm{kg}$ orally for experimental rats with glutathione-depleted mice caused extensive necrosis in the center of the Centrilobular liver within 24 hours (Mizutani et al. 1987). BHT between 0.01-0.5 \% for 12 days led to increased liver weight in white mice, and increased dose to $800 \mathrm{mg} / \mathrm{kg}$ liver destruction occurred. Polyethelene and BHT films used in packing Fillet fishes for 120 days under $-25^{\circ} \mathrm{C}$ showed tissue damage and loss in firmness (Torres-Arreola et al. 2007).

The use of BHT at $200 \mathrm{ppm}$ caused the significant increase in the activities of enzymes relevant to the functions of liver and kidney, in contrast, caused marked pathological changes in liver and kidney of rats (El-Anany and Ali 2013)

The aim of this research was to study the effect of PE, BHT, PE+ BHT, and the thermally-treated PE on the liver of adult male mice.

\section{Materials and Methods}

\section{Experimental animals}

Adult male Albino Mice (MF1) with similar weights, 45 days old were used in the current examination and were obtained from the King Fahd Center for Medical 
and Technical Research at King Abdul Aziz University, Jeddah, KSA.

\section{Nutritional experiments}

A total of 105 adult male Albino Mice, 3 were placed in each cage and fed with a mixture of yellow corn, some plant fiber, vitamin A, amino acids, folic acid, calcium salts, phosphorus, iron and potassium, and supplied with normal water (12 hours light and 12 hours of darkness). The mice were left in the laboratory for two weeks before the experiments were carried out to adapt to the laboratory temperature (18$20 \mathrm{~m}$ ) and surrounding conditions. They were again weighed at the end of the trial period (42 days) and prior to autopsy to study variations in growth measures among group members and compare them with the control group. The animals were then divided into two groups; the first with 60 animals were used for the toxicity test and divided into 6 sub-groups (10 mice each). They were subjected to treatments with different concentrations of PE and BTH for 7 days for determination of the lethal dose (LD), half lethal $\left(\mathrm{LD}_{50}\right)$, and under $\mathrm{LD}_{50}$ (sub LD). The second group composed of (45 animals) and divided into 5 groups (every 9 animals), to study the effect of PE, BHT, and the thermal PE bags on liver tissue, and also the behavioral and phenotypic changes in weights, in biochemical measurements, and histological changes that took place during the trial period (42 days).

\section{Materials and Chemicals Kit}

PE: From Sabic Company, a mixture of PE powder with rat food was prepared at a rate of $4 \mathrm{gm} / \mathrm{kg}$ body weight, and different concentrations were prepared $(2,4,6,8 \mathrm{gm} / \mathrm{kg})$.

BHT: From Sabic Company, 1.5 gm were dissolved in $9 \mathrm{ml}$ of corn oil, and different concentrations were prepared $(0.5,1.0,1.5,2.0,2.5 \mathrm{gm} / 9 \mathrm{gm}$ corn oil) Doses were administered to rats through a metal tube (feeding tube) $50 \mathrm{~mm}$ in length, $2.25 \mathrm{~mm}$ in diameter.

\section{Formalin $10 \%$ was used as a fixative solution}

Hematoxylin and Eosin stains were used for liver histological staining.

AST and ALT kits were obtained from SPINREACT CO. (ref; 41272, 001172 respectively, Spain). All chemicals used were of analytical reagent grade.

\section{Toxicity Tests:}

1- Control: Two groups each 5 rats one fed with corn oil, the other kept with no feeding.

$2-$ PE group: 6 groups 10 rats each, daily fed with $\mathrm{PE}+$ specially mixed food, each given different rate $0.5,1.0,1.5,2.0,2.5 \mathrm{mg} / \mathrm{kg}$ body weight.

3 - BTH group: Divided into 4 groups each 10 rats, and fed through mouth daily different rates of BTH+specially prepared diet 400, 650, 780, 850 $\mathrm{mg} / \mathrm{kg}$ body weight throughout the period of the experiment.

\section{Test of Liver Tissue:}

The second group of 45 rats was divided into 5 each with 9 rats.

1 - Control: given balanced food with corn oil by mouth.

2 - PE group: Fed with $4 \mathrm{mg} / \mathrm{kg}$ PE mixed with balanced food according to ((Kalinin et al. 1964; Sheftel 1977; Michailets et al. 1978).

3 - BHT group: Fed with $400 \mathrm{mg} / \mathrm{kg}$ of BTH dissolved in $1.5 \mathrm{ml}$ of corn oil according to (Lanigan and Yamarik 2002).

$4-\mathrm{PE}+$ BHT group: Fed with $4 \mathrm{mg} / \mathrm{kg}$ PE mixed with balanced food and $400 \mathrm{mg} / \mathrm{kg}$ of BTH dissolved in $1.5 \mathrm{ml}$ of corn oil. 
5 - Thermal PE bags group: Fed with balanced food heated to more than $1000 \mathrm{C}$ and put inside PE bags.

\section{Blood sampling:}

Animals were anesthetized after injection by diethyl ether and blood samples $(0.5-1.0 \mathrm{~mm})$ were collected directly from the cardiac heart puncture by means of the capillary tube (1-1.5 m) from each rat. The blood of rats in each group was centrifuged at $1,100 \mathrm{Xg}$ for $20 \mathrm{~min}$ to obtain the sera are stored frozen $\left(-20^{\circ} \mathrm{C}\right)$ until further analysis. The serum biochemical was analyzed ALT and AST activities were measured according to the methods described by Bergmeyer and Harder 1986 and Belfield and Goldberg 1971, respectively.

\section{Histopathological study}

The liver was cut into small pieces $\left(5 \mathrm{mg}^{3}\right)$ and immersed into formaldehyde $10 \%$, and dehydrated with absolute alcohol $100 \%$ for 2 hrs, then in xylol solution, and subjected to infiltration with melted paraffin wax. The paraffin-embedded section was placed in special boxes and cold water was poured for solidification of wax. The samples were cut into slides using a microtome $(5-6 \mu)$, and then stained using Haematoxylin and Eosin to Culling 1965, and wax was removed using xylol and alcohol in a decreasing order $100 \%$ - up to $70 \%$ for 5 minutes.
Sections were put on glass slides, a drop of Canada balsam was added, and now ready for test using an ordinary optical microscope (20 magnification) for histological evaluation.

\section{Statistical analysis}

Data were statistically analyzed in a completely randomized design in a factorial arrangement according to the procedures outlined by Gomez and Gomez 1984 and the treatments mean were compared by least significant differences (L.S.D) and Duncan multiple ranges using SPSS program package.

\section{Results and Discussion}

\section{Toxicity Tests:}

PE tests: All the animals fed with the special food mixed with PE for 7 days remained alive with all concentrations. None of the concentrations is lethal.

BTH tests: All animals fed with food mixed with 400 $\mathrm{mg} / \mathrm{kg}$ body weight of BHT for 7 days remained alive, $50 \%$ of the animals died when administered doses of $650 \mathrm{mg} / \mathrm{kg}, 75 \%$ animals died under dose of 780 $\mathrm{mg} / \mathrm{kg}$, and all animals (100\%) died when given a dose of food mixed with BHT up to $860 \mathrm{mg} / \mathrm{kg}$ body weight. Based on these results, the lethal dose of half $\mathrm{LD}_{50}$ for BHT was $650 \mathrm{mg} / \mathrm{kg}$ (body weight), the sub-LD of BHT was $780 \mathrm{mg} / \mathrm{kg}$, and the dose of 860 $\mathrm{mg} / \mathrm{kg}$ is the LD that is toxic to BHT (Fig. 1).

Table 1 Results of toxicity tests by PE and BHT

\begin{tabular}{|c|c|c|c|c|}
\hline Groups & No. of animals & Dose $(\mathrm{mg} / \mathrm{kg})$ & No. died & Death rate \\
\hline Control & 10 & -- & -- & $0 \%$ \\
\hline PE group & 10 & $0.5-2.5$ & -- & $0 \%$ \\
\hline BHT 1 & 10 & 400 & -- & $0 \%$ \\
\hline BHT 2 & 10 & 650 & 5 & $50 \%$ \\
\hline BHT 3 & 10 & 780 & 7 & $70 \%$ \\
\hline BHT 4 & 10 & 860 & 10 & $100 \%$ \\
\hline
\end{tabular}






Fig. 1: lethal doses of BHT

\section{Behavioral \& Observations}

\section{Results:}

Some behavioral changes have been observed on experimental animals. These changes vary depending on the stages of the experiment.

A) In the first phase of the experiment, the mice became very aggressive while placing them in cages.

B) The animal group fed on food-mixed with PE, which was deprived of food for 24 hours, were observed refusing to eat for 30-45 minutes when they sniffed and left food after a period of eating gradually.

C) The BHT group animals were observed to have fainted after the oral feeding, which lasts for 2060 seconds.
D) Animals of the BHT group after 21 days of oral feeding were observed to hid themselves in sawdust.

E) Decreased appetite for all animals, especially the group that fed the PE, and therefore became severely weak. These results agree with Sheftel (1977) who observation changes in the behavior of animals when given different doses of (PE), and with Lanigan and Yamarik (2002) who noticed a reduction in the appetite of animals for food and water when treated with BHT.

\section{Body Weight:}

The body weight results showed significant variations among the treated rat's body weights due to the different treatments (table 2). Body weight of treated animals showed a significant reduction compared to untreated animals (table 2) (Fig. 2). 
Table 2: Means of rats body weight (gm)

\begin{tabular}{|c|c|c|c|}
\hline \multirow[b]{2}{*}{ Groups } & \multicolumn{2}{|c|}{ Mean \pm SD } & \multirow[b]{2}{*}{$\begin{array}{l}\text { Body wt. } \\
\text { reduction \% }\end{array}$} \\
\hline & $\begin{array}{l}\text { Rat body wt. } \\
\text { before treatment } \\
\text { (gm) }\end{array}$ & $\begin{array}{l}\text { Rat body wt. after } \\
\text { treatment (gm) }\end{array}$ & \\
\hline Control & $30.85 \pm 0.508$ & $35.57 \pm 0.71$ & \\
\hline PE group & $31.00 \pm 0.816$ & $25.57 \pm 0.36$ & 19 \\
\hline BHT 2 & $31.14 \pm 0.508$ & $25.85 \pm 0.59$ & 19 \\
\hline PE + BHT & $30.142 \pm 0.67$ & $22.84 \pm 0.57$ & 27 \\
\hline Thermal PE & $30.57 \pm 0.84$ & $33.71 \pm 0.56$ & 9 \\
\hline
\end{tabular}

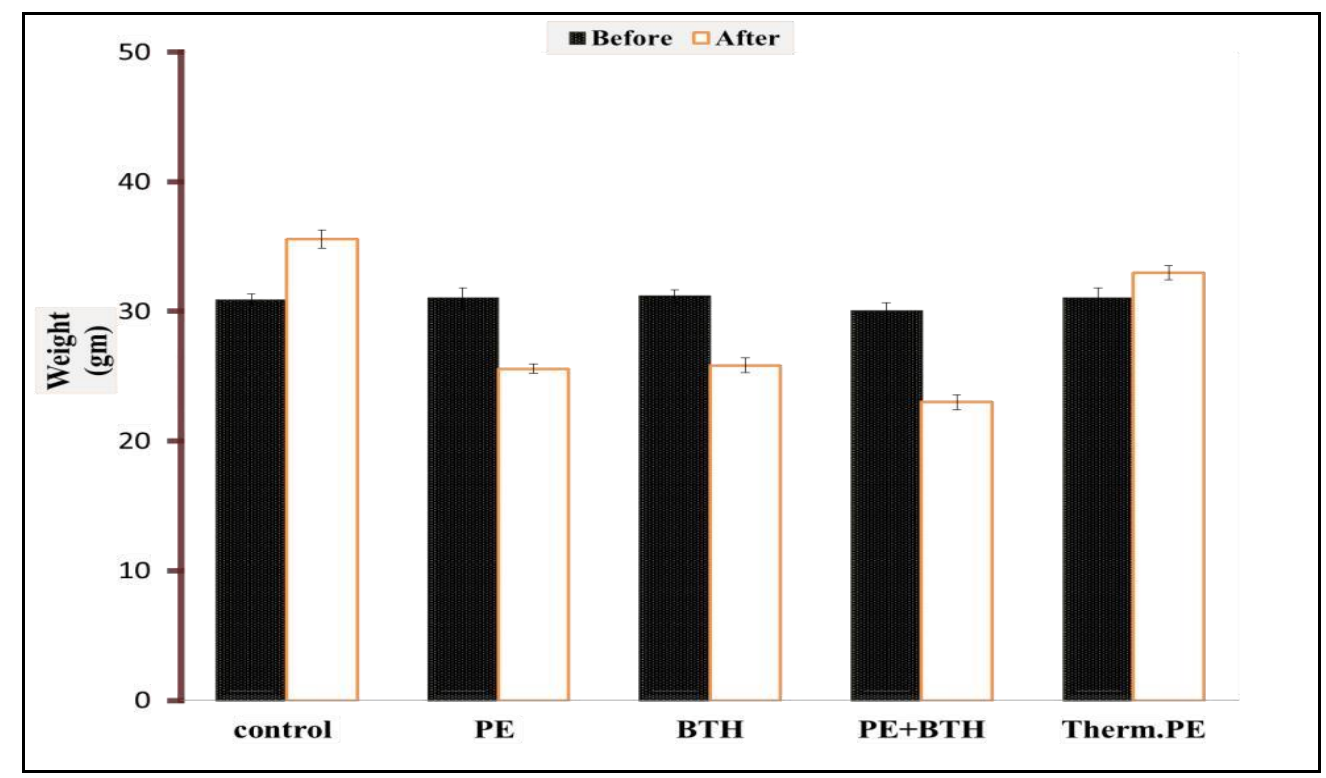

Fig (2): Body wt. of rats before and after treatments

The most affected rats are those fed with PE + BHT with a reduction in their body weight up to about $27 \%$ seconded by those treated with PE and BHT with a reduction in wt. up to about $19 \%$. The rats treated with thermal PE have body wt. reduction of up to $9 \%$ only. These results agree with the finding of Sheftel (1977) who observation reduction in the body weight of rats given different doses of (PE), and with Mayer and Hansen(1980) who fed infant rats 500, mg/kg BHT, and with Lanigan and Yamarik (2002) who treated rats with $\mathrm{BHT}$, but differ from findings of Kalinin et al. (1964) who fed rats $2.5 \mathrm{~g}$ of PE powder and found no change in body weight, and also differed from the study of Michailest et al. (1978), who gave rats $1.25 \mathrm{~g}$ of high density $\mathrm{PE}$ and observed no significant toxic effects. 


\section{Liver weight:}

Table 3 shows the mean liver weighs of the animal groups after the end of the experiment. The highest mean weights of the liver are in the PE group $(2.33 \pm$ $0.064 \mathrm{gm})$, the BHT group $(2.61 \pm 0.13 \mathrm{gm})$, and in the PE and BHT group $(0.103 \pm 2.88$ gm $)$ which increased significantly $(\mathrm{P}<0.01)$ at percentages of
$43.83 \%, 61.12 \%, 77.78 \%$ respectively compared to control group mice $(1.62 \pm 0.126 \mathrm{gm})$. The mean weight of the liver in the thermally treated PE group $(1.63 \pm 0.081 \mathrm{gm})$ showed no significant change from the liver in control group mice $(1.62 \pm 0.126 \mathrm{gm})$. These results agree with the finding of Nakagawa et al. (1984) who found a significant increase in rat liver treated with PE, and BHT.

Table 3 Means of rat liver weight (gm)

\begin{tabular}{|c|l|l|}
\hline & Rat liver wt. $($ gm) & Liver wt. increase \% \\
\hline Control & $1.62 \pm 0.126$ & -- \\
\hline PE group & $2.33 \pm 0.064$ & 43.83 \\
\hline BHT 2 & $2.61 \pm 0.13$ & 61.12 \\
\hline PE + BHT & $2.88 \pm 0.103$ & 77.78 \\
\hline Thermal PE & $1.63 \pm 0.081$ & -- \\
\hline
\end{tabular}

\section{Effect on AST, ALT activities}

Enzymes play a vital role in the evaluation of functions of the liver so levels of the two (AST) and (ALT) were determined. Table 4 illustrates the means of the concentrations of AST and ALT under the effects of the different treatments. AST and ALT concentrations increased significantly ( $\mathrm{P}<0.01)$ under all treatments, PE gave the highest concentrations $741.42 \pm 18.958$ and $295.42 \pm 19.614$ $\mathrm{U} / \mathrm{L}$ respectively for AST, ALT, seconded by BTH
$502.14 \pm 12.23 \mathrm{U} / \mathrm{L}$ in case of AST, and by the treatment PE + BHT with $280.42 \pm 22.25 \mathrm{U} / \mathrm{L}$ in the case of ALT, the treatment with the third level of AST is $\mathrm{PE}+\mathrm{BHT}$ with $335.42 \pm 14.5$, and the third level of ALT is BHT with $179.71 \pm 11.213 \mathrm{U} / \mathrm{L}$. The treatment with the lowest AST and ALT is the thermal PE with $202.14 \pm 3.093$ and $121.42 \pm 18.481$ $\mathrm{U} / \mathrm{L}$ respectively. This finding does not agree with the result of Elgazar (2013) who treated rats with 0.4 and $0.8 \mathrm{mg} / \mathrm{kg}$ BHT and found a reduction in AST and ALT levels. 
Table 4 means of the concentrations of AST and ALT under the effects of the different treatments.

\begin{tabular}{|c|l|l|}
\hline \multirow{2}{*}{ Groups } & \multicolumn{2}{|c|}{ Mean \pm SD } \\
\cline { 2 - 3 } & AST (U/L) & ALT (U/L) \\
\hline Control & $96.71^{*} \pm 1.409$ & $27.85 \pm 2.303$ \\
\hline PE group & $741.42 * \pm 18.958$ & $295.42 \pm 19.614$ \\
\hline BHT 2 & $502.14 * \pm 12.23$ & $179.71 \pm 11.213$ \\
\hline PE + BHT & $335.42 * \pm 14.5$ & $280.42 \pm 22.25$ \\
\hline Thermal PE & $202.14 * \pm 3.097$ & $121.42 \pm 18.481$ \\
\hline
\end{tabular}

Data are expressed as mean $\pm \mathrm{SD}$

Values given represent means of six determinations.

*. The mean difference is significant at the 0.05 level between groups.

The results indicated that rats fed on a diet containing PE and BHT suffered a reduction in body weight, enlargement of the liver, a disorder in the function of the liver observed in the high concentration of AST, and ALT.

\section{Effects on Liver Histological Structures:}

Figure 3 shows a transverse section of the part of the liver of the control group near the Central Vein $(\mathrm{CV})$ region. Hepatocyte cells $(\mathrm{H})$ are observed arranged in rows separated by sinusoidal sinuses (S). The Hepatic cells have round nuclei and cytoplasm with base pigmentation, and hepatothelial cells (S) tend for base pigmentation. The liver structure has normal order.

Under treatment with PE, the liver lost its normal cell structure, and many dark hepatic cells appeared stained with Eosin, indicating that it has been affected, also the presence of atrophy, while the rest of the cells are enlarged and have a large cellular cavity near the nucleus, (Fig. 4), and near the pylori region there is damage in the vascular endothelium with blood hemorrhage (Fig. 5).

Under BHT treatment the hepatic cells are darkly stained, irregular in shape with nucleic atrophy which is signs of Apoptosis and the cytoplasm is granulated with a relative expansion of the liver sinusoids (S) (Fig. 6). The beginning of liver fibrosis is clear, hepatocytes $(\mathrm{H})$ are large in size, with large nuclei, and abnormal chromatin shape, and loss of regularity, compared to the control group (Fig. 7).

This is in agreement with that indicated by both Mizutani et al. (1987) and Nakagawa et al. (1984) and Torres-Arreola et al. (2007).

The transverse sections of the liver of the $\mathrm{PE}+$ BHT group appear with many darkened cells having dark-colored nuclei with eosin dye and some damaged cells and the onset of hyperplasia. Some liver cells are malignant, with haemorrhage, some sections show the destruction of the epithelial lining, and atrophy and destruction of the hepatic cells becoming dark under dye of the eosin with areas of 
hemorrhage, and some shows severe portal vein tension (PV) and bile duct dysfunction (BD), severe hepatocyte dysfunction is observed with haemorrhage (Figs. 8, 9 and 10). This is in agreement with the results obtained by Takahashi and Hiraga (1978) and Torres-Arreola et al. (2007).
In view of the thermal PE group, severe congestion in the veins (V) and the bile ducts (BD), with obvious rupture in the liver cells, resulting in the loss of the liver lobules of their normal form. The increase in the number of central veins $(\mathrm{CV})$ in the same area for the occurrence of atrophy in the liver tissue compared to the control group (Figs. 11).

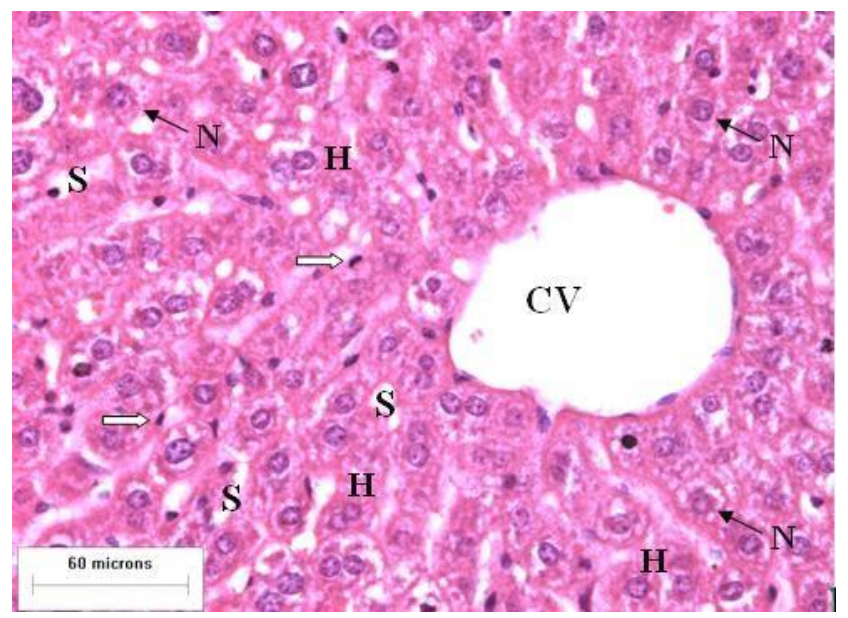

Fig. 3 Transverse section of liver of control group. Normal arrangement of cells. CV (Central Vein), N (nucleus), H (cell), S (sinusoid).

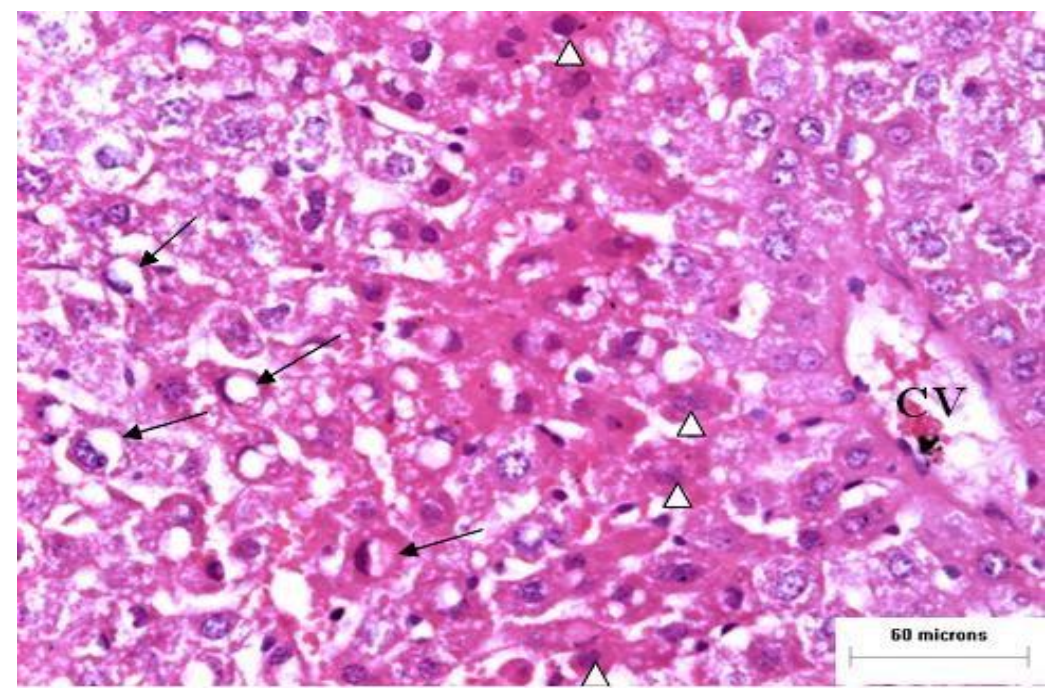

Fig. 4 Transverse section of liver of PE group. Most of cells lost arrangement, appeared dark In color, with apoptosis $(\Delta)$, some cells appeared inflated and had a large cellular cavity near the nucleus, which appeared crescent shape $\uparrow$. 


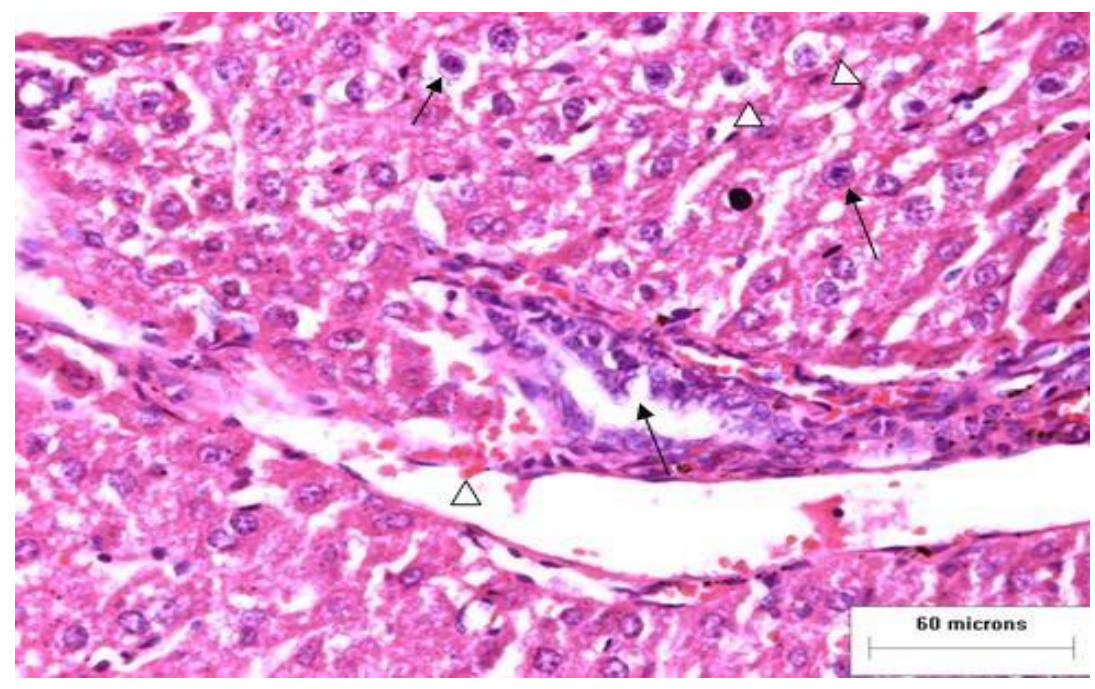

Fig. 5 Transverse section of liver of PE group near the pyloric area. Shows damage in vascular endothelium $(\Delta)$, with hemorrhage, as well as the bile duct $\uparrow$ and the emergence of hepatic cells as abnormal and malignant. The bile duct appears surrounded by a homogeneous homotoxin.

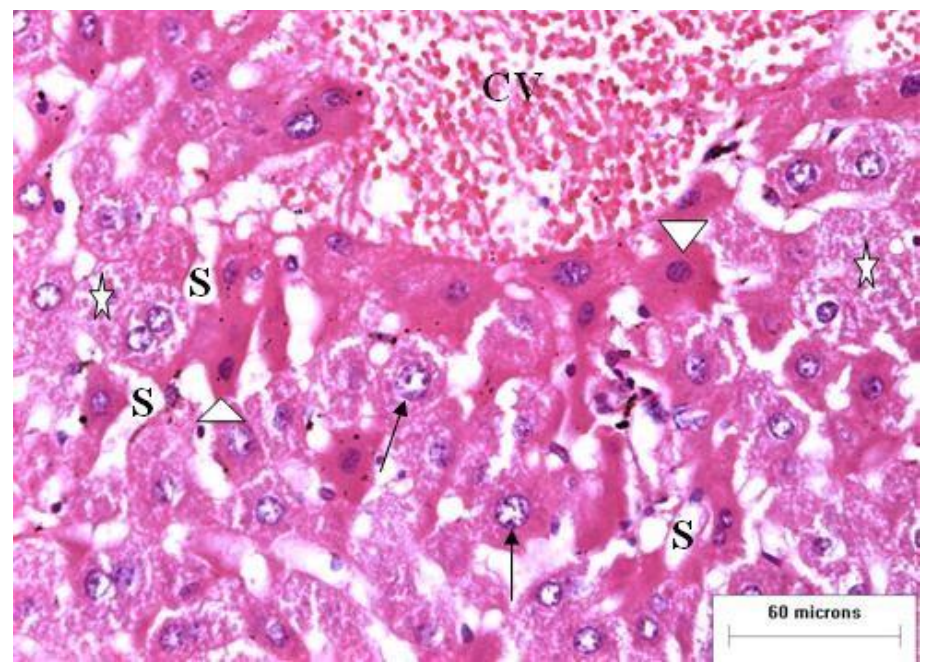

Fig. 6 Transverse section of liver of BHT group. Dark liver cells with irregular shape $(\Delta)$ and have dark nuclei (Nicrosis). Other cells are enlarged and have granular cytoplasm, and some have large-sized nuclei ( $\uparrow$ ) and relative expansion of the sinuses $(\mathrm{S})$. 


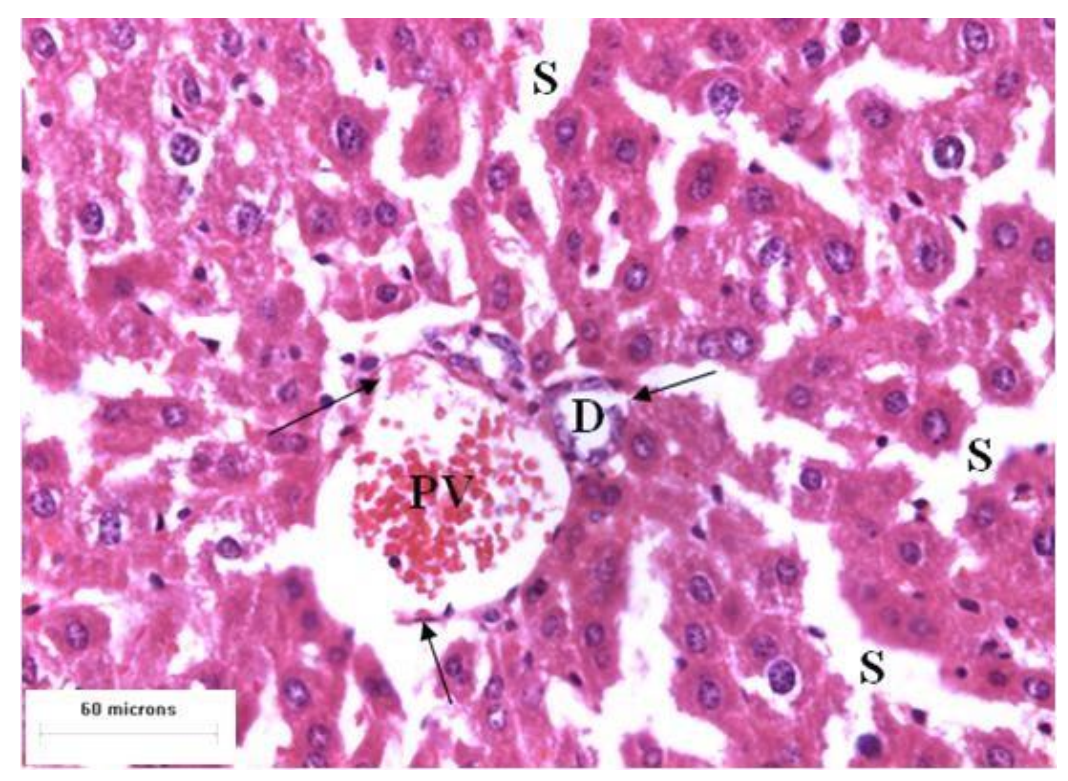

Fig. 7 Transverse section of liver of BTH group near the pyloric region. Hepatocellular congestion (PV) and damage in the bile duct (BD) as well as portal vein $\uparrow$ and atrophy and necrosis of hepatic cells, which appeared unclear and have lost their normal order and also the relative enlargement of the hepatic sinuses $(S)$ and irregularity of their shape.



Fig. 8 Transverse section of liver of the $\mathrm{PE}+\mathrm{BHT}$ group shows severe portal vein tension (PV) and bile duct dysfunction (BD) 个, severe hepatocyte dysfunction is observed with haemorrhage ( 


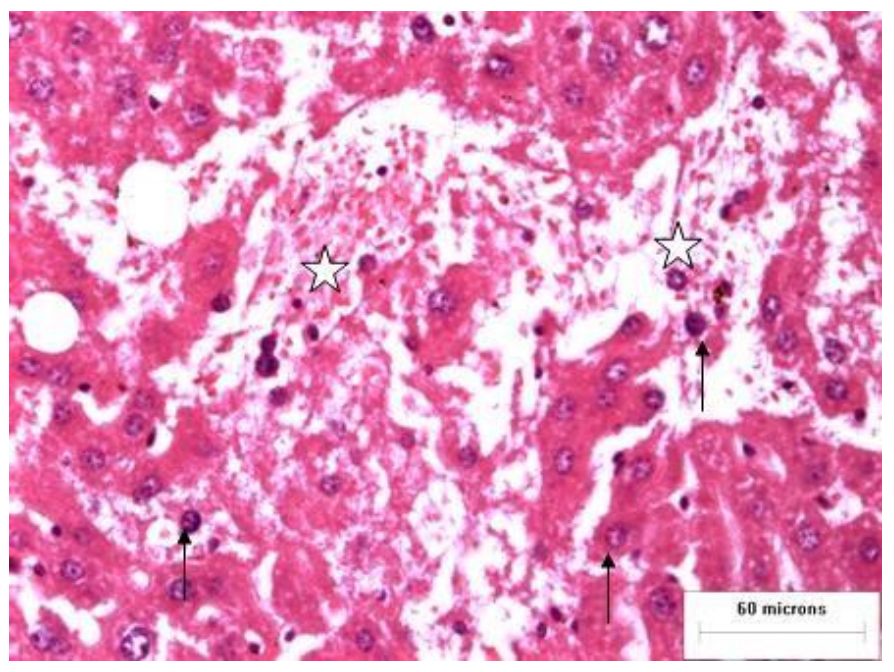

Fig. 9 Transverse section of the liver of the PE + BHT group showing, severe malformation, hepatic cell cirrhosis, and the onset of cirrhosis ( $(\hat{z})$. The other cells appeared with atrophy and unclear border.

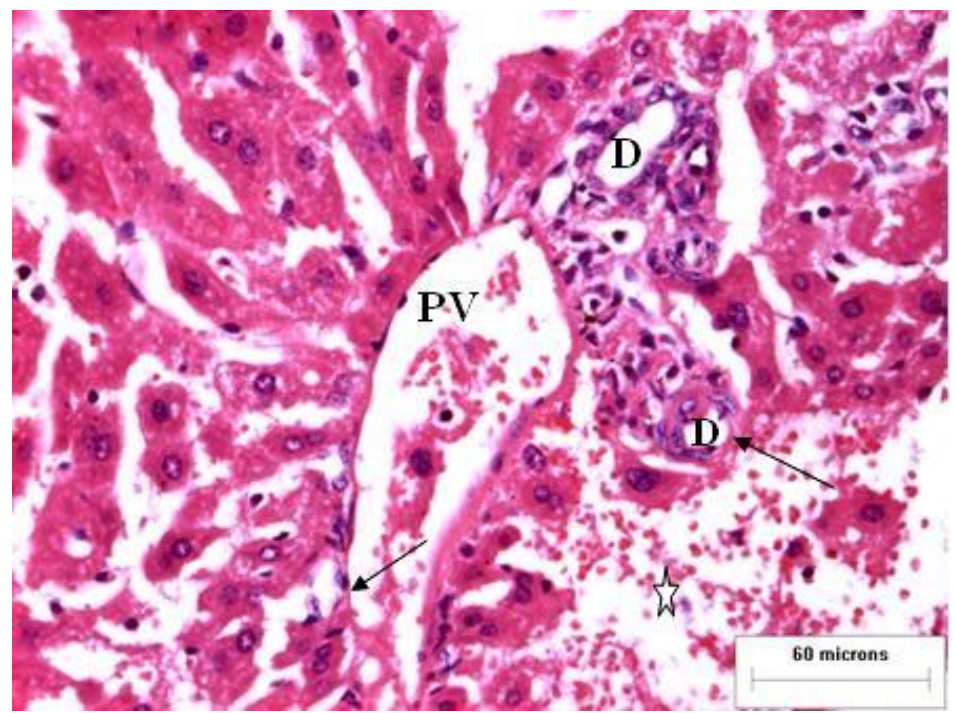

Fig. 10 Transverse section of the liver of the PE + BHT group near the pylori area shows bile ducts and the portal vein (PV) destructed epithelial lining $\uparrow$, and the hepatic cells appear atrophic, dilute, and dark stained with eosin with areas of hemorrhage ( $\left.\begin{array}{c}5 \\ \text { ) }\end{array}\right)$. 


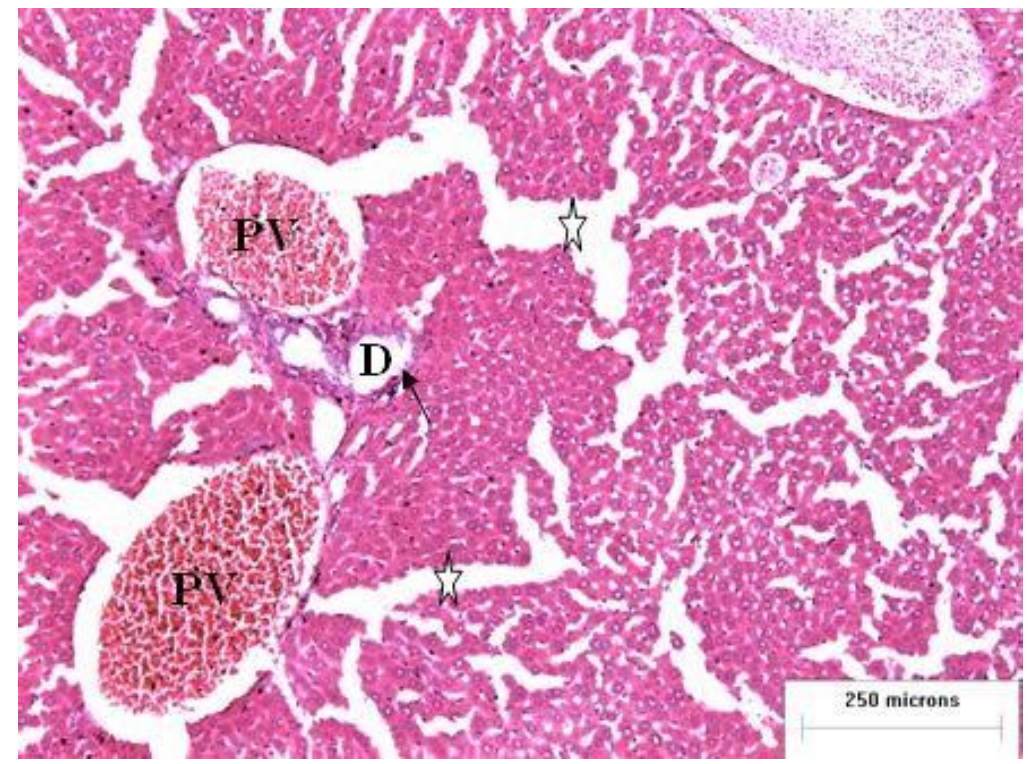

Fig. 11 T.S. of a liver in the thermal PE group The congestion and severe expansion of the portal veins (PV) with rupture of the hepatocytes $(\mathrm{H})$, which leads to the loss of hepatic lobules of their normal form, expansion of the bile ducts (D) and atrophy of the epithelial lining, is also observed.

Figs. 1-10 1 Microscopical examination of liver tissues of rats given only the basal diet (control) (H.E $X$ 200). 2 Microscopical examination of kidney tissues of rats given only the basal diet (control) (H.E $X$ 200). 3 Histological examination of liver tissues of rats administered the basal diet and BHT (200 ppm.) (H.E X 200). 4 Histological examination of kidney tissues of rats administered the basal diet and BHT (200 ppm.) (H.E X 200). 5 Cross-section of liver tissues of rats administered the basal diet and Pomposia fruit juice (200 ppm.) (H.E X 200). 6 Cross-section of kidney tissues of rats administered the basal diet and Pomposia fruit juice (200 ppm.) (H.E X 200). 7 Cross-section of liver tissues of rats administered the basal diet and Pomposia fruit juice (400 ppm.) (H.E X 200). 8 Cross-section of kidney tissues of rats administered the basal diet and Pomposia fruit juice (400 ppm.) (H.E X 200). 9 Cross-section of liver tissues of rats administered the basal diet and Pomposia) fruit juice (1,200 ppm.) (H.E X 200). 10 Cross section of kidney tissues of rats administered the basal diet and Pomposia fruit juice (1,200 ppm.) (H.E X 200) 


\section{CONCLUSION}

Treatment of adult male rates with PE, BHT, PE + BHT, thermal PE resulted in changes in behavior and changes in body weight and liver function and histology. Rats became aggressive and tend to be isolated, accompanied by a lack of appetite. The treatments resulted in a decrease in body weight, an increase in liver weight, an increase in the enzymes AST, ALT, changes in liver histology. Examination under the PE group revealed a loss of lobular architecture with the appearance of deeply stained liver cells and atrophic nuclei (Apoptotic changes), and under BHT group showed congestion of the central and portal veins with destruction in the epithelial covering layer of the biliary canaliculi and portal veins, and under the treatment $\mathrm{PE}+\mathrm{BHT}$ the effects are more significant with atrophy of the liver cells that appeared as small deeply stained cells with small atrophic nuclei with the appearance of liver fibrosis and loss of lobular architecture with severe congestion of portal veins and bile canaleculi and atrophy of the epithelial lining layer of these veins and canaliculi, with a significant increase in AST and ALT levels in blood in comparison to the control group.

Loss of arrangement and rupture of hepatocytes, damage in vascular endothelium, with hemorrhage, and the emergence of hepatic cells as abnormal and malignant. The bile duct appears surrounded by a homogeneous homotoxin, necrosis, hepatocellular congestion (PV) and damage in the bile duct (BD) as well as the portal vein, and atrophy and necrosis of hepatic cells, severe malformation, hepatic cell cirrhosis and the onset of cirrhosis and loss of hepatic lobules of their normal form. The effects are more significant under the treatment of $\mathrm{PE}+\mathrm{BHT}$ compared to PE alone or BHT alone. Thermal PE is the least effective treatment of rats.
Bergmeyer HU, Harder M (1986) A colorimetric method of determination of serum glutamic oxaloacetic and pyruvic transaminase. Clin Biochem 24:28-34.

Elgazar AF (2013) Effects of Butylated Hydroxytoluene and Butylated Hydroxyanisole Against Hepatotoxicity Induced by Carbon Tetrachloride in Rats. World Applied Sciences Journal 22 (1): 63-69.

Hamoud MH (2003) Tissue Science. El Ahlia for Publishing and Distribution, Oman.

Kalinin B, Zimnitskaya Yu, Zalesskaya LP (1964) Toxic properties of stabilized lowpressure polyethylene, in Toxicology and Hygiene of HighMolecular-Mass Compounds and of the Chemical Raw Material Used for Their Synthesis, Proc. $2^{\text {nd }}$ AllUnion Conf., A. A. Letavet and S. L. Danishevsky, Eds., Khimiya, Leningrad, 110 (in Russian).

Lanigan RS, Yamarik TA (2002) Final Report on the Safety Assessment of BHT1. International Journal of Toxicology 21(2):19-94.

Meyer O, Hansen E (1980) Behavioral developmental effects of BHT dosed to rats in utero and in the lactation period. Toxicology 16:247-58.

Michailets B, Sukhareva LV, Yevsyukov VI (1978) Hygienic characteristics of highdensity polyethylene made with help of vanadium catalysts, in Environmental Protection in Plastics Production and Hygiene Aspects of Their Use,

\section{REFERENCES}


Plastpolymer, Leningrad, 99 (in

Russian).

Mizutani T, Nomura H, Nakanishi K, Fujita S

(1987) Hepatotoxicity of butylated hydroxytoluene and its analogs in mice depleted of hepatic glutathione. Toxicol. Appl. Pharmacol 87: 166-176.

Nakagawa Y, Hiraga K, Suga T (1984) Preventive effect of cysteine effect of cysteine on butylated hydroxytoluene-induced pulmonary toxicity in mice. Biochem. Pharmacol .33:502.

Sheftel VO (1977) Hygiene Aspects of the Use of Polymeric Materials in the Water Supply, Thesis Diss., All-Union Research Institute of Hygiene and Toxicology of Pesticides, Polymers and Plastic Materials, Kiyv, 61 (in Russian).

Shehata HA (1998) Environmental pollution, the problem of the virus, its causes and its solution. College of Science. Al Azhar University.

Takahashi O (1991) Some properties of rat platelet aggregation and effects of butylated hydroxytoluene, warfarin and aspirin. Food Chem. Toxicol 29:173- 183.

Takahashi O, Hiraga K (1978) Dose-response study of hemorrhagic death by dietary butylated hydroxyl-toluene (BHT) in male rats. Toxicol. Appl. Pharmacol 43:399-406.

Torres-Arreola W1, Soto-Valdez H, Peralta E, Cardenas-López JL, EzquerraBrauer JM (2007) Effect of a low-density polyethylene film containing butylated hydroxytoluene on lipid oxidation and protein quality of Sierra fish (Scomberomorus sierra) muscle during frozen storage. J Agric Food Chem 55(15):6140-6.

Verhagen, H, Beckers HHG, Comuth PAWV, Maas LM (1989) Disposition of single oral doses of BHT in man and rat. Food Chem.Toxicol 27:765-772.

Yamamoto K, Tajima K, Okino N, Mizutani T (1988) Enhanced lung toxicity of butylated hydroxytoluen e in mice by coadministration of butylated hydroxyanisole. Res. Commun. Chem. Pathol. Pharmacol 59: 219-231.

Zitting A. and Savolainen H. (1979): Fire Mater; 3:80-83 